\title{
Levator palpabrae superioris myositis as an unusual cause of unilateral ptosis-case report
}

\author{
Ahmed M. Abdrabou(D)
}

\begin{abstract}
Background: Ptosis can be a manifestation of a more serious situation. Hence, the analysis of the complaint and the search for etiology are crucial in such cases. Ptosis has many causes; some of them lead to unilateral ptosis while others cause bilateral ptosis. For instance, myasthenia gravis is a cause of bilateral ptosis while oculomotor nerve palsy induces unilateral disease. Proper evaluation of the patient and identification of the cause are important to achieve accurate management and good prognosis.

Case presentation: A 47-year-old male patient attended the ER complaining of dropping the right eye lid of 2 days' duration. There was no associated pain or diplopia. On examination, the extraocular muscles' (EOM) motility was intact, normal pupil and corneal reflexes, and there was swelling of the upper eyelid. Ophthalmological examination revealed normal anterior and posterior chambers as well as the vitreous and retina. The patient had a previous history of traumatic intracranial hemorrhage that was resolved without surgical intervention. He also had diabetes mellitus and hypertension. The patient was transferred to the MRI unit to perform MRI study of the brain and orbit with MRA and IV contrast administration. MRI findings confirmed the diagnosis of LPS myositis, and the patient received medical treatment and improved.
\end{abstract}

Conclusion: Proper radiological diagnosis leads to accurate management and achieves rapid recovery and optimal patient care.

Keywords: LPS, Orbit, Ptosis, Myositis

\section{Background}

Ptosis can be a manifestation of a more serious situation. Hence, the analysis of the complaint and the search for etiology are crucial in such cases. Ptosis has many causes; some of them lead to unilateral ptosis while others cause bilateral ptosis. Myopathies, like myasthenia gravis, causes weakness of extraocular muscles and subsequently bilateral ptosis while selective oculomotor nerve injury leads to unilateral eye drop. Proper evaluation of the patient and identification of the cause are important to achieve accurate management and good prognosis.

Correspondence: ahmed.abdrabou@med.asu.edu.eg

Radiology Department, Faculty of medicine, Ain shams university, Cairo, Egypt

\section{Case presentation \\ Patient information}

A 47-year-old male patient attended the ER complaining of dropping the right upper eyelid for the past 2 days. There was no associated pain or diplopia. The patient had a previous history of intracranial hemorrhage that was resolved without surgical intervention. He also had diabetes mellitus and hypertension.

\section{Clinical findings}

On examination, the extraocular muscles' (EOM) motility was intact, normal pupil and corneal reflexes, and there was swelling of the upper eyelid. Ophthalmological examination revealed normal anterior and posterior chambers as well as the vitreous and retina.

\section{Springer Open}

(c) The Author(s). 2021 Open Access This article is licensed under a Creative Commons Attribution 4.0 International License, which permits use, sharing, adaptation, distribution and reproduction in any medium or format, as long as you give appropriate credit to the original author(s) and the source, provide a link to the Creative Commons licence, and indicate if changes were made. The images or other third party material in this article are included in the article's Creative Commons licence, unless indicated otherwise in a credit line to the material. If material is not included in the article's Creative Commons licence and your intended use is not permitted by statutory regulation or exceeds the permitted use, you will need to obtain permission directly from the copyright holder. To view a copy of this licence, visit http://creativecommons.org/licenses/by/4.0/. 


\section{Diagnostic assessment}

The patient was transferred to the MRI unit to perform MRI study of the brain and orbit with MRA and IV contrast administration.

The study showed diffuse enlargement of the levator palpabrae superioris (LPS) muscle with increased signal intensity on T2-WI (Fig. 1) and significant enhancement on post-contrast T1 fat-suppressed images (Fig. 2). The edema and enhancement involved the muscle belly and tendinous attachment. The superior rectus muscle could be seen normally beneath the swollen muscle. The diagnosis of isolated LPS myositis was established on a radiological basis .

\section{Therapeutic intervention}

Following the diagnosis, the patient started oral steroid therapy (prednisolone) and improved dramatically after 4 days. Follow-up visit in the neurology clinic after 2 weeks revealed complete recovery.

\section{Discussion}

Levator palpabrae superioris (LPS) muscle is the main muscle that retracts the upper eyelid and keeps the eye open. It arises from the annulus of Zinn, like most of the extraocular muscles, and courses above the superior rectus muscle. It has a triangular shape with its apex directed posteriorly and fans anteriorly toward its insertion into the tarsal plate of the upper eyelid as well as the skin of the upper eye lid. Its innervation comes from the oculomotor nerve (CN III), and hence, it can be affected in CN III injury [1-3].

The etiology of ptosis has a wide differential diagnosis. They can be classified into neurogenic and myogenic causes. Examples of neurogenic causes include CN III palsy which can be partial or complete and usually affects more than a single muscle. It can be a result of PCOM aneurysm which compresses the nerve at its cisternal segment or due to microvascular disease, e.g., in DM and hypertension which cause partial CN III palsy. Other neurogenic causes include Horner's and GuillainBarre syndromes. Myasthenia gravis, on the other hand, is an example of myogenic causes which causes muscle weakness and bilateral ptosis [4].

Orbital myositis is a subtype of an idiopathic orbital inflammatory syndrome (IOIS) which affects the extraocular muscles causing ophthalmoplegia, ptosis, and pain [2]. It can affect single or multiple muscles and can occur with other inflammatory diseases, e.g., rheumatoid arthritis, systemic lupus erythromatosis (SLE), sarcoidosis, and IgG4-related diseases $[5,6]$. Isolated myositis of the LPS is rare and few cases were described in the literature [4].

In cases of ptosis, MRI study with intravenous contrast administration is the imaging modality of choice
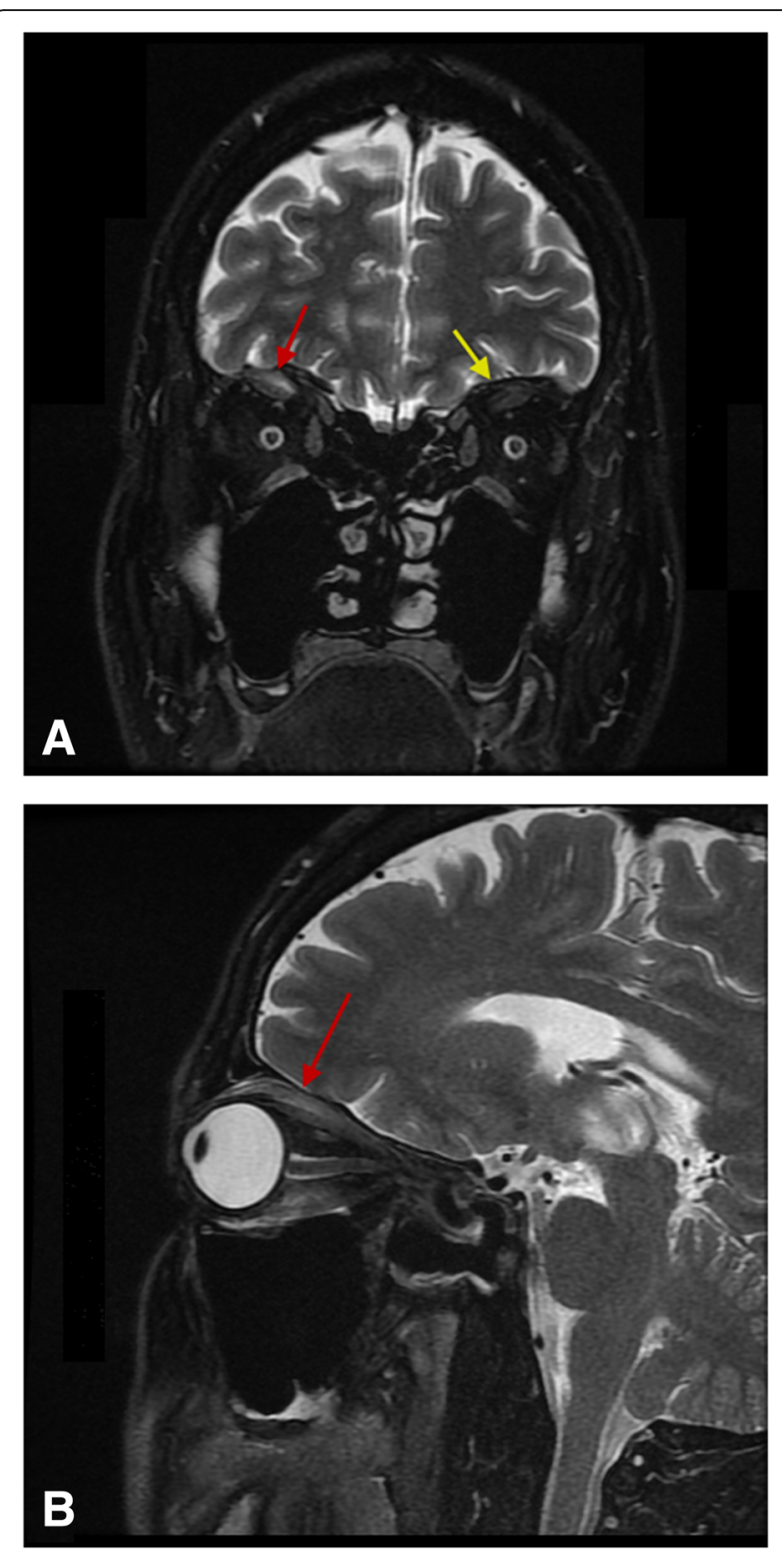

Fig. 1 a T2 FS coronal image and $\mathbf{b}$ T2 FS sagittal image of the right eye. They displayed diffuse enlargement of the right LPS muscle (red arrow), which displayed bright signal on T2, as compared to the contralateral normal muscle (yellow arrow). The right superior rectus muscles, on either side, are seen unaffected

[5]. Imaging findings of orbital myositis include diffuse enlargement and abnormal enhancement of the affected muscle, which involve the muscle belly and tendinous attachment. In systemic disease, e.g., sarcoidosis, other findings can be also seen, for example, lacrimal gland infiltration and dural enhancement of the optic nerve sheath [5, 7]. It is worth to mention that, in our case, the laboratory tests for rheumatology factor, e.g., SLE, and anti-nuclear antibody (ANA) were negative. 

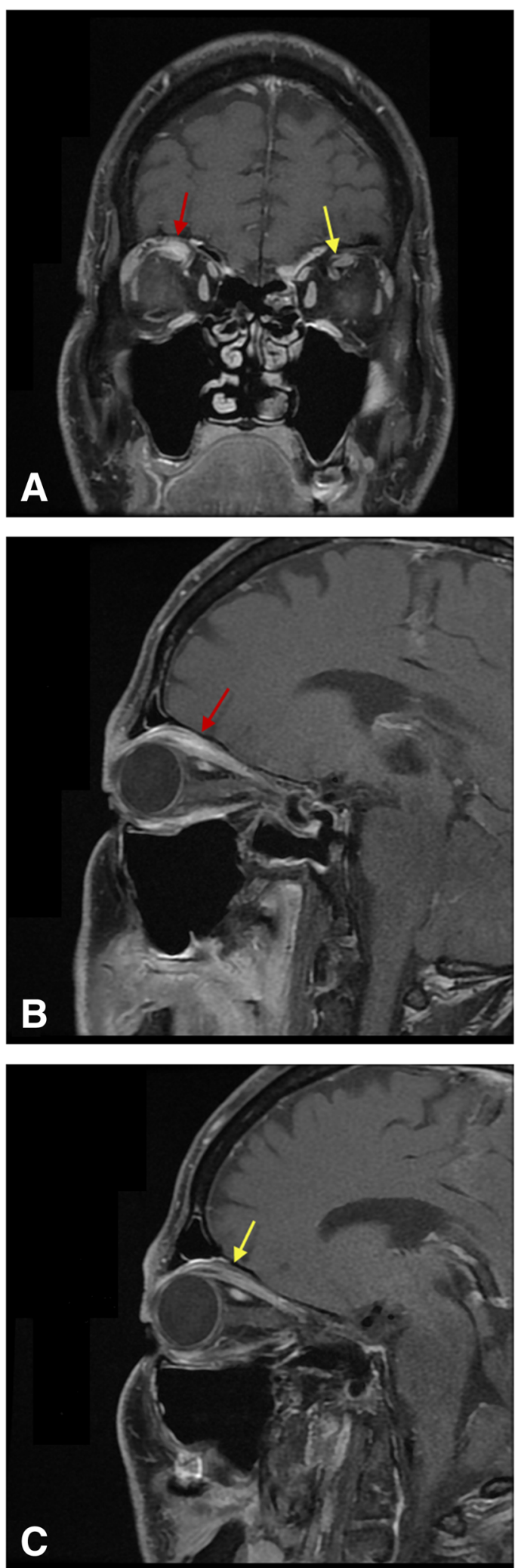

Fig. 2 a T1 FS coronal image with IV contrast, b T1 FS sagittal image with IV contrast of the right eye, and $\mathbf{c}$ of the left eye. They displayed diffuse enhancement of the swollen LPS on the right side (red arrow) which involved the tendinous insertion as well. Note the normal appearance of the superior rectus muscle on the right side. On the left side, the LPS (yellow arrow) showed normal size and enhancement as the rest of the extraocular muscles

\section{Patent perspective and informed consent}

The patient was satisfied with the rapid recovery; he handed out a thank-you letter for the author and agreed to sign a consent to publish this case report.

\section{Conclusion}

Proper radiological diagnosis achieves accurate management which leads to rapid recovery and optimal patient care.

\section{Abbreviations}

LPS: Levator palpabrae superioris; EOM: Extraocular muscles; DM: Diabetes mellitus; PCOM: Posterior communicating artery; CN: Cranial nerve; IOIS: Idiopathic orbital inflammatory syndrome; SLE: Systemic lupus erythromatosis; ANA: Anti-nuclear antibody; IgG4: Immunoglobulin G4

\section{Acknowledgements}

None

\section{Author's contributions}

AMA did the data collection, analysis, and interpretation; also he writes the manuscript and approves the submission. The author(s) read and approved the final manuscript.

\section{Funding}

None

\section{Availability of data and materials}

The original, PACS generated, study images are available to the reviewers upon request.

\section{Declarations}

Ethics approval and consent to participate

Ethical approval is not required for the publication of isolated case reports.

The patient was informed about the procedure, and a written informed consent was obtained.

\section{Consent for publication}

Written informed consent was obtained from the patient for publication of this case report and accompanying images and is available upon request.

\section{Competing interests}

The author declares no competing interests.

Received: 6 January 2021 Accepted: 21 March 2021

Published online: 01 April 2021

\section{References}

1. Ng SK, Chan WO, Marcet MM, Kakizaki H, Selva D (2013) Levator palpebrae superioris: an anatomical update. Orbit 32(1):76-84. https://doi.org/10.3109/ 01676830.2012 .736602

2. van der Pol CB, Chakraborty S, Gao J, Nguyen T, Torres C, Glikstein R (2014) Imaging anatomy and pathology of extraocular muscles in adults. Can Assoc Radiol J 65(4):366-371

3. Turvey TA, Golden BA (2012) Orbital anatomy for the surgeons. Oral Maxillofac Surg Clin 24(4):525-536. https://doi.org/10.1016/j.coms.2012. 08.003 
4. Court JH, Janicek D (2015) Acute unilateral isolated ptosis. BMJ case reports 2015:bcr2014207720. https://doi.org/10.1136/bcr-2014-207720

5. Kirac LB, Cakar A, Turkoglu Y, Ak H-C, Coskun D, Ustun-Ozek S, Uçler-Yaman S, Baykan B (2018) Orbital myositis: an underrecognized clinical syndrome with a need of management guidelines. Can J Neurol Sci 45(1):121-125. https://doi.org/10.1017/cjn.2017.258

6. Espinoza GM (2010) Orbital inflammatory pseudotumors: etiology, differential diagnosis, and management. Curr Rheumatol Rep 12(6):443-447. https://doi.org/10.1007/s1 1926-010-0128-8

7. Thatcher J, Chang Y-M, Chapman MN, Hovis K, Fujita A, Sobel R, Sakai O (2016) Clinical-radiologic correlation of extraocular eye movement disorders: seeing beneath the surface. RadioGraphics 36(7):2123-2139. https://doi. org/10.1148/rg.2016150227

\section{Publisher's Note}

Springer Nature remains neutral with regard to jurisdictional claims in published maps and institutional affiliations.

\section{Submit your manuscript to a SpringerOpen ${ }^{\circ}$ journal and benefit from:}

- Convenient online submission

- Rigorous peer review

- Open access: articles freely available online

- High visibility within the field

- Retaining the copyright to your article 